\title{
The Restoration of Paper Documents and Manuscripts
}

This monograph describes what is being done by librarians to preserve and restore books, manuscripts, and archival materials. It discusses the following problems: (1) flattening of folded documents; (2) the methods used by librarians to restore collections damaged by fire and water. Included is a summary of some of the procedures used by the librarians at the Jewish Theological Seminary of America library and in Florence to restore damaged collections. Among the methods discussed are quick freezing and drying in microwave ovens; (3) restoration of documents is discussed with reference to the following procedures: (a) silking; (b) tissue process; (c) washing and bleaching; (d) inlaying, framing and glazing; (e) sprays; (f) lamination and laminating films.

M

ANUSCRIPT and archival material are primary sources of information. As such, they are of inestimable value to researchers in every field. Many of these documents and books, particularly those printed or written on paper manufactured since the introduction of the Fourdrinier paper machine in 1827 , have begun to deteriorate. This deterioration is due to the lowering of the quality of paper and other materials used for printing and writing, and to the fact that manuscripts and archival materials have been stored under adverse conditions. Age and use have also contributed to the deterioration of materials. The great increase in the use of manuscripts and archival material has focused the attention of librarians on the problem of preservation and restoration and the need to develop programs in their respective libraries that will attempt to solve this problem.

Mr. Cutter resides at 1345 East 10th Street, New York City.
Preservation and conservation programs should make provisions for:

1. Proper storage conditions that will prevent the deterioration of materials.

2. Prevention of the loss of materials due to destruction by fire, water, insects, and theft.

3. Preservation and restoration of materials.

It is the purpose of this paper to describe briefly what is being done and should be done by libraries pertaining to the preservation and restoration of materials.

"Treatment of the paper stock is usually the first requirement in the repair or reconditioning of manuscripts or old books." It is therefore essential, for the librarian to know what causes the deterioration of paper stock in order that he may develop a program that will curtail it and devise means to repair deteriorated documents. Paper is largely

${ }^{1}$ Harry M. Lydenberg, The Care and Repair of Books (New York: Bowker, 1960), p.63. 
made of matted cellulose fibers derived from wood, rags, or other fibrous materials. It is sized with rosin glue or caesin in order to prevent the spreading of writing ink. The best grades of paper are made from high quality rags or wood pulp and have a high alpha-cellulose content. Little bleaching or chemical treatment is required in their manufacture. The quality of cellulose used in the manufacture of paper largely determines the strength and durability of paper. The higher the alpha-cellulose content of the paper, the less it will be affected by careless handling and the less it will be affected by exposure to heat, light, dry air, sulphur dioxide fumes, excessive dampness, and dust so frequently present in storage areas. ${ }^{2}$

"Papers dating from the last half of the nineteenth century generally cause the greatest concern, because it was during this period, that the paper-making machine came into widespread use and many inferior fibers were adopted at random to meet the needs of the suddenly increased production and the accelerated demand for paper products." 3 These papers, for the most part, have a very low alpha-cellulose content, and their deterioration is greatly accelerated by one or any combination of the aforementioned factors.

As was customary before the close of the nineteenth century, papers were folded and put away in poorly designed containers eventually to be relegated to some attic or equally unsuitable place. Therefore, when an attempt was made to open these papers, they often cracked along the fold lines. Flattening manuscripts thus became a time-consuming step in preservation. It is therefore evident from the above that the quality of the paper, the extent to which manuscripts and documents have been used,

${ }^{2}$ Adelaide E. Minogue, "Physical Care, Repair and Protection of Manuscripts," Library Trends, V (January 1957), 344-45.

${ }^{3}$ Ibid., p.348. and the condition under which they have been stored affect their condition.

Flattening documents usually makes them more easily accessible and easier to preserve. To accomplish this, one can place brittle papers in a humidifying chamber. If papers are exposed to an atmosphere of 90 to 95 per cent humidity, they will become flexible and will not break when unfolded. When these documents are subsequently packed firmly in storage containers, folds will be less evident and to a great extent nonexistent. If the documents are very creased, they can be smoothed in a mangle or with a hand iron or a pile of blotters. $^{4}$

"In certain cases, documents require special treatment in flattening." Adelaide Minogue advocates that "fragile items such as brittle tracing papers, documents that have been washed or bleached to remove stains, fragments of mildewed, water soaked, or burned documents, and parchments, which do not tolerate ironing, may be more safely handled by spreading out each dampened sheet between blotters and pressing, without heat, until dry."

Flattening vellum and parchment manuscripts is quite problematic because one must be extremely careful not to allow water to come into direct contact with the sheet. This is particularly true in the case of illuminated manuscripts. After dehumidifying, Lydenberg suggests that single sheets be attached to a frame of wood, slightly larger than the sheets to be treated, with weights fastened to the perimeter of the frame. "The sheet can be so adjusted that there will be an even pull in all directions and the moisture will permit it to be flattened evenly. ... The drying should be gradual and sometimes (where otherwise mold might develop) it may be well to apply artificial

\footnotetext{
4 Lucile M. Kane, A Guide to the Care and Administration of Manuscripts (Nashville: American Association for State and Local History, 1966), p.42-43.

${ }^{5}$ Ibid., p.43.
} 
heat if the heat can be kept well under control. $^{6}$

After all pieces that need it have been flattened the collection should be carefully inspected to determine if any of the materials need treatment, mending, or restoration. This is particularly true of new acquisitions which will not be processed for sometime and if stored in their present condition may cause deterioration of other materials in the collection. Lucile Kane suggests that the following initial steps be taken to clean newly acquired materials:

"Damp sheets are dried between blotters to prevent mold, mildew, and other damage to ink and paper. If the repository has standard fumigating equipment, manuscripts are freed from insects, rodents, and fungi by exposure in tanks. Few small institutions have fumigating chambers. In their absence, it is recommended that the papers be exposed to the vapors of ethylene dichloride and carbon tetrachloride in an airtight box for twentyfour hours and then thoroughly aired."

Dust and abrasives, such as sand and plaster, and surface dirt that will smear when the papers are placed in storage, must be removed before the papers are disturbed in any way. Minogue states: "Rubbing the records with a cloth or using any suction method may merely spread the dust into the papers or tear them along the edges." This is particularly true of papers dating from the last half of the nineteenth century. She recommends that "streams of air be blown along the exposed edges of the papers." Lucile Kane further states that the manuscripts "be placed under a hood that sucks up dust" during this process. She also suggests that materials be cleaned with soft brushes or a paste type wall paper cleaner. ${ }^{9}$

' Lydenberg, op. cit., p.76.

Kane, op. cit., p.10-11; Minogue, op. cit., p.346; Arthur E. Kimberly, "Repair and Preservation in the National Archives," American Archivist, I (July 1938) 111-12.

${ }^{5}$ Minogue, op. cit., p.348.

${ }^{9}$ Kane, op. cit., p.10-11.
The latter suggestion is questionable to some authorities, however, because such pastes under certain conditions can foster the growth of mold and mildew.

Other problems that must be considered that are not peculiar to any period or to any type of record are the following:

1. Records damaged as a result of fire and water or insects.

2. Restoration of documents.

3. Storage and shelving. (This topic is beyond the scope of this paper and will not be discussed.)

\section{Records Damaged as a Result of WATER OR FIRE}

Much can be learned in this regard from the experience of librarians now involved in the restoration of books and manuscripts at the Jewish Theological Seminary in New York and at libraries in Florence.

On April 18, 1966, fire raged in the Jewish Theological Seminary library. The fire "destroyed about seventy thousand volumes. The materials on the two uppermost levels were almost completely consumed. . . . materials on the third level from the top were partly burned, partly heavily damaged by water or by the collapsing shelves. A small portion of the materials on the third level was salvaged. The seven lower stacks containing some 150,000 volumes were heavily damaged by water."10

Under the leadership of Menahem Schmelczer, the librarian of the seminary, a plan for salvaging the damaged collection was initiated. All books were removed from the stacks and set up in free standing areas in order that the books be exposed to the maximum amount of circulating air. This was done because circulation of air and the rapid removal of excess moisture are the most effective

\footnotetext{
${ }^{10}$ Menahem Schmelczar, "Report on the Library of the Jewish Theological Seminary of America," (January 1-September 30, 1966).
} 
ways known to prevent the development of mold and mildew. Fans and dehumidifiers were used to speed the process of drying. Trays of calcium chloride were placed in all book storage areas to absorb moisture from the air. Temporary shelves were erected in many storage areas in order to increase the area available for drying books. The faculty and library staff selected books considered important or rare for priority treatment.

New methods to dry books were suggested and experimented with. The experiments included quick-freezing, and drying in microwave ovens. "Although both were successful-that is, they did dry books-both the mechanical facilities and skilled personnel to operate them were in short supply. All the appropriate quick-freeze facilities in the East, had they been available, could handle a maximum of 150 books a week -not an encouraging forecast to a library staff faced with a thousand times that number. Proper use of this technique required operators familiar with defrosting rates and temperatures, and these too proved scarce. Similar difficulties were encountered with the microwave ovens, although as many as four of these were used in the early stages of the salvage operation." 11

The use of thymol chambers was experimented with in order to dry books and to arrest the onset of mold and mildew. The experiment proved to be highly successful. This experiment was discontinued because of the lack of facilities to handle large quantities of books and the fact that the time involved was prohibitive.

Interleaving with paper towels in lieu of blotters, although time consuming, proved to be the most successful method of drying books. This was because of the availability of many volunteers, and of plentiful supplies.

\footnotetext{
${ }^{11}$ Majorie Wyler, "Need Calls Forth New Techniques for Book Salvage Following Library Fire in New York," The Weekly Underwriter, CXCIV (June 25, 1966), 26.
}

Books that had begun to mildew and mold in spite of preventive measures, were treated with alcohol. Fumigation with formaldehyde was considered but not used to any extent because: (1) the conditions under which formaldehyde can be sprayed are astringent; (2) no fumigator could be found with the proper facilities; and (3) experts in the field indicated that alcohol would do an adequate job.

Many bindings were damaged by water, and others by efforts to dry the leaves and to remove mold and mildew. In other instances, bindings had to be removed because it was found that glue on the spines, when wet, caused the growth of mold and mildew. This necessitated undertaking a massive binding operation of damaged volumes, procedures of which are beyond the scope of this paper. Some of the materials charred by the fire required considerable inlays; others required minor repairs. The library was advised by W. J. Barrow to deacidify and laminate with cellulose acetate film and tissue some of the damaged material. Material of considerable importance that was completely burned through may be photographed on infrared film at a future date.

Similar problems, although on a grander scale, were encountered by conservators sent to Florence by the Committee to Rescue Italian Art (CRIA), on a factfinding mission on November 14, 1966. "Professor Bates Lowry, chairman of the committee's national executive committee, said that the combination of water, mud, and seeping fuel oil from furnaces and tanks which engulfed buildings, works of art, books, and manuscripts, presented unprecedented problems for conservators."12 Menahem Schmelczer, one of sixteen conservators sent by the committee on this mission, describes in an unpublished report some of the methods used to treat damaged books. Tem-

${ }^{12}$ New York Times (November 18, 1966), 88. 
porary shelving was erected and nets spread out between chairs and tables to dry books. Waterlogged books were interleaved. Books were also sent to tobacco-processing plants and drying areas equipped with dehumidifiers, chemicals to absorb moisture, and electric fans. The Florentine synagogue arranged to send untreated books to the Sime factory of electrical appliances. "Books were spread out on little hand trucks and put into electric ovens for drying at a temperature of about $45^{\circ}$ centigrade. The doors of these ovens were left a little bit open to allow for the circulation of air. After forty-eight hours the books became almost completely dry. Since most of the books were printed before the nineteenth century, the good quality paper was seemingly not affected by the relatively high temperature. When the books dried, it was easy to separate papers which were previously stuck together because of wetness." Conservators planned to create thymol chambers by placing plastic sheets over shelving areas and heating thymol crystals to the level of evaporation within the chamber. It was hoped that books could be kept within the chamber for two to three days before they were put back on shelves set aside for dry books. This method was found to be effective in the past in combating mildew and in disinfecting books.

When this job is done, these damaged books and manuscripts will have to be restored. This is indeed one of the important steps in preservation.

\section{Preservation and Restoration}

Several processes are now being used by libraries to preserve weakened and deteriorated documents. The restorer must select the materials to be restored and decide upon the process to be used. He must bear in mind that "nothing should be done that will seriously impair the usefulness of the manuscript or later result in serious damage to it."13 There are three basic requirements which any satisfactory restoration process should meet. They are:

1. Legibility. The readability of the restored item should not be reduced appreciably.

2. Permanency. In order to insure permanency, the impurities which caused deterioration of the item should be removed or made inert. The materials used to strengthen the sheet should be chemically pure and stable and should be resistant to the harmful action of certain agents present under normal storage conditions and usage. In addition, the process used should not reduce the permanency of the item treated.

3. Durability. After restoration, items which will get much use should have both good resistance to tearing and folding endurance. Seldom used items, such as exhibit pieces may have a lower requirement. ${ }^{14}$

Cost is also a factor to be considered.

The following are the most commonly used processes for the restoration of deteriorated manuscripts and books.

\section{Silk Process}

The silk process consists of pasting to each side of the document a piece of semi-transparent, coarsely woven silk cloth, often with a flour paste containing acidic alum. The end product will have relatively good visibility, be strong, and have a high resistance to tearing. In time this resistance is lessened because silk is not a stable product. Gradually it begins to discolor and tends to become brittle. The paste used in its application dries out and embrittles the whole sheet. Often too it is attacked by insects and mold.

\footnotetext{
${ }^{13} \mathrm{~W}$. J. Barrow, "Deacidification and Lamination of Deteriorated Documents, 1938-1963," American Archivist, XXVIII (April 1965), 285.

14 Roy O. Hummel and W. J. Barrow, "Lamination and Other Methods of Preservation," Library Trends, IV (January 1956), 260.
} 
In addition to the gradual deterioration of silk, the silking process makes no provision for neutralizing and/or eliminating the factors which caused the deterioration. Silking is a slow and expensive process. The skilled labor needed to apply it is difficult to find. For these reasons, silking has ceased to be considered a satisfactory method of permanent restoration, and its use has fallen into disfavor in recent years. ${ }^{15}$

\section{Tissue Process}

The tissue process is similar to silking. For reasons of economy, thin sheets of tissue made of high grade fibers are used in lieu of silk. This process, too, has limited use, in view of the fact that no provision is made for eliminating the active compounds in the sheet that caused deterioration. The process is slow, and the end product has a low tear resistance. ${ }^{16}$

In conclusion, Barrow's comment should be noted-"While these processes have made possible continued use of many deteriorated documents, in general both processes have a limited life expectancy of twenty to thirty years." ${ }^{17}$

\section{Mending}

Mending in the strict sense of the word, is not a restorative process and does not add strength to the leaf or volume being repaired. Only papers and manuscripts that have not begun to deteriorate can be mended. Japanese tissue and paste or transparent "mending" tape can be used to repair torn pages or to reinforce leaves. If it becomes necessary to fill out incomplete leaves, the restorer should use paper of the same grade, thickness, and texture as the original leaf. In order for these to match, he has two alternatives. He may either darken the area that was repaired with a solution of tea or coffee to match the original leaf or (and this is more difficult and

\footnotetext{
${ }^{15}$ Ibid., p.260-61; Barrow, op. cit., p.285; Minogue, op. cit., p.351.

${ }^{16}$ Hummel, op. cit., p.261; Barrow, op. cit., p.285.

17 Barrow, op cit., p.285.
}

not preferable) he may bleach the repaired area to match the original sheet if paper of a darker shade is employed to fill out an incomplete leaf. This process should include the reproducing in facsimile of missing words and letters. Perforations can be filled in by means of a paste filler made of paper fluff and paste, or paper pulp. ${ }^{18}$

\section{WASHING AND BLEACHING}

Documents may be washed, preferably in distilled water, or they may be sponged with water and soap jelly to free them from dust and grime. Washing can, in certain instances, restore some life to brittle and dry papers. Some of the acidity inherent in paper may be removed. ${ }^{19}$

Stains of a more permanent naturei.e., iodine, mildew, or mold-may be removed by the application of such solvents as benzene, benzole, gasoline, or alcohol. Minogue recommends that "the paper itself should be laid with the stained side down on a white blotter and the solvent be sponged on from the back. ... As the solvent is applied successively, the paper should be moved to clean portions of the blotter. When repeated sponging leaves no significant residue on the blotter, the paper should be turned over and treated in a similar way as on the stained side. After the solvent has dried, no ironing or other flattening treatment should be required."20

Documents are sometimes bleached to remove discoloration stains or to lighten darkened documents in order to increase the legibility of the writing or print of the documents involved. The use of potassium permanganate and potassium metasulphate has given way to bleaching agents which are simpler to use and safer. The foremost bleaching agent in

\footnotetext{
${ }^{18}$ Lydenberg, op. cit., p.64; Hummel, op. cit., p.261.

19 Hummel, op. cit., p.261; Lydenberg, op. cit., p.265.

${ }^{20}$ Lydenberg, op. cit., p.67-68. (Includes a list of recommended solvents); See also, Minogue, The Repair and Preservation of Records $[$ Bulletins of the National Archives, Number 5.j (Washington: 1943).
} 
use today is Chloramine T. Although it is supposed to be safer than other bleaching agents in use, it is questionable whether it has the same lightening effect. Lydenberg describes its application: "A two percent solution is painted on the surface to be cleaned with a fine flat brush. The treated leaf is placed between blotting paper and boards and pressed in a book press or under weights. The treatment may be repeated after one hour, until a satisfactory appearance is achieved." It has also been found that the use of Chloramine $\mathrm{T}$ is effective in removing discoloration due to foxing. ${ }^{21}$

R. J. Gettens developed a procedure for the use of sodium chlorite as a bleaching agent. Its application is more complex than the application of Chloramine $\mathrm{T}$. The document or leaf to be treated is submerged in a tray containing a 2 per cent solution of sodium chlorite plus five ounces of 40 per cent formaldehyde. It is suggested that the document be submerged for fifteen minutes. The length of submersion is dependent upon the intensity of the staining, and therefore it is conceivable that the document may be submerged for a longer period of time. The document is then rinsed in running water for the same length of time that it was submerged in the solution, and then dried between blotters. Other bleaching agents also being used include oxalic acid, javelle water, and ammonia. ${ }^{22}$

A word of caution is in order here. Chlorine bleaches should be used under very carefully controlled conditions as chlorine can be deleterious to cellulose fibers. Any lowering in the strength of the document-i.e., folding endurance or tear resistance-should be evaluated against the legibility of the writing or the print of the document involved. Minogue states: "Except for oily stains, which may be removed with a dry cleaning solvent, it is best not to tamper with stains or discolorations. The chemicals required, mainly acids and bleaches, will seriously weaken cellulose fibers and destroy the sizing. It is likewise inadvisable to try to restore the legibility of faded iron-gall inks by chemical means, but if faded documents can be photographed by ultraviolet light using fluorescence filter, the print will be considerably more legible than the original. If an examination or reading of the document will suffice, it will be observed that the ink residue will fluoresce and become legible to the eye as well as to the camera." ${ }^{23}$

Many deteriorated documents will crumble if an attempt is made to erase surface dirt, even with a soft eraser. Water may damage paper, particularly coated, highly glazed paper. Writing inks, particularly of oak gall origin, may run. Solvents may dissolve printing ink. Bleaching chemicals can weaken paper if they are not thoroughly removed. Therefore the restorer must be certain prior to employing this process, that the method and material he chooses will not further damage the document in question. It is suggested that both the paper and ink be tested to determine whether they will withstand the treatment chosen to restore them. For example, ink can be tested by applying a drop of water to an inconspicuous part of the text. The restorer can tell whether the print or writing ink is likely to come off by touching a blotter on the spot. In sum therefore great emphasis should not be placed on this method as a satisfactory means of restoration for the following reasons1 . The process is relatively slow since sheets must be treated individually;

2. The appearance of the document may be enhanced by the process but not the strength of the document;

3. Materials and methods employed may, under certain circumstances, cause further deterioration of the materials being restored.

${ }^{23}$ Minogue, op. cit., p.350-51. 


\section{REsIZING}

A common process to strengthen deteriorated papers and improve the coherence of the fibers of the papers is resizing. This process consists of dipping the document into a bath of two to four per cent animal glue, gelatin, starch, or material of similar content. In the light of recent research, one can question the feasibility of this process. Hummel states: "Some recent research has shown, however, that many deteriorated papers have lost their sizing and this has not been the cause of the weakening of most paper. Since too much size will stiffen a sheet and make it less flexible, there is no reason to think that resizing will add much strength to a deteriorated sheet. It is also true that modern wood pulp paper contains noncellulose materials which have no fiber structure. Sizing will have little or no value in trying to bind together components of such paper."24

\section{Inlaying, Framing, Glazing}

Inlaying or framing is another means of reinforcing papers. Through this method the margins of a single sheet of paper are extended by framing it with a larger sheet. This method is used particularly in the repair of documents for display purposes or in illustrating books when the restorer wishes to make the inserted illustrations the same size as that of the book into which they are being inserted. Hummel does not think that this is a satisfactory method of restoration because the process is slow and tedious and because framing adds little strength to the sheet. Second, "inlaying may result in the formation of undesirable cockles and a premature breakdown of the original sheet" due to the fact that the rate of expansion and contraction resulting from the change in temperature and humidity is seldom the same in two different papers. ${ }^{25}$
Glazing is similar to the above process. The document is mounted between sheets of glass bound together at the edges or framed. Glass that absorbs the short wave lengths of light which are deleterious to paper should be used in order to protect the document from light. The document is flattened and subsequently held in place tightly by the pressure between the pieces of glass or the backing of the frame. This process also protects the document from dust. ${ }^{26}$

\section{Preservation of Materials in Plastic Envelopes}

Carolyn Horton recommended this method of preservation to the Jewish Theological Seminary for their "Genizah" manuscripts. In a letter addressed to Miss Kleban of the library she states: "All materials used are of the most permanent nature and the protection which this type of treatment gives . . . is the most complete possible short of sealing them in a vacuum chamber in a fireproof vault. The manuscripts can be examined without being touched directly, typed or written comments or translations can be written on interleaving pages, an index can be written or typed on the front page and the pages can be removed for photography or possible rearrangement in some future age."

The specifications suggested were as follows:

"The pages are made of permalife paper which is acid free and designed for permanence.

"The envelopes are made of Lumarith L-822, the gauge thickness being .0075 , the optimum thickness for durability. ... The envelopes are held together with non-rusting aluminum alloy post binders. The binding is constructed of 'Gold Label' binders board, the most durable available in the world and the covering material is of Bancroft Legal Buckram. ... In tests made by the Lakeside Press

\footnotetext{
${ }^{2 n}$ Minogue, op. cit., p.28.
}

${ }^{25}$ Ibid., p.263.

${ }^{24}$ Hummel, op. cit., p.262. 
this cloth stood up to accelerated aging tests better than any other available." 27

This method as was previously indicated is being used by the Jewish Theological Seminary library and has proved to be quite satisfactory.

\section{SPRAYS}

Conservators hoped that sprays consisting of a transparent coating (perhaps a plastic film that would be applied to the surface of the document) would be developed and prove to be economical as well as protective. To date however, "no worth while spray method of restoration has been developed." Earlier sprays composed of cellulose nitrate are now considered "to be unstable and injurious to paper." Other sprays "gave a protective coating to the surface of the paper but added little to its physical strength. It has been shown that they sometimes increase the brittleness of the paper. Nor do they remove or neutralize whatever chemical impurities were in the sheet originally and these are left to continue the process of deterioration." 28

\section{LAMINATION}

Lamination is the modern counterpart of the silking and tissue processes. It is a process by which a sheet of thermoplastic cellulose acetate film is applied by precision-built equipment to each side of a sheet of paper by means of controlled heat and pressure. This method was first used in the mid-1930's as a means of restoring deteriorated materials. Testing revealed that lamination "protects the sheet from some adverse external influences but it does not add sufficient strength to withstand the normal stresses of flexing and does not provide the resistance to tearing so necessary for normal use. Like the silk and tissue process, it does not neutralize or inactivate the components that cause the papers to be-

${ }^{27}$ Carolyn Horton, Letter addressed to Miss Anne Kleban, March 3, 1963.

${ }^{28}$ Hummel, op. cit., p.262. come increasingly brittle. Consequently, like the other two, this method has limited value from the standpoint of preservation and use." 29

Lamination experiments were also conducted with cellulose containing thermoplastic and pressure-sensitive adhesives. It has been found that this procedure is satisfactory for use on materials of temporary value. It is not satisfactory for use on manuscripts of permanent value, or books, because the film tends to peel off after a few years, leaving the adhesive embedded in the pores of the paper. Moreover, the adhesive sometimes discolors the paper. This material, too, does not provide the resistance to tearing so necessary for normal use. ${ }^{30}$

William Herbert Langwell, the noted British conservator advocates the use of the "Sundex" process, a process similar to the Barrow process. He claims that this process has some advantages over the Barrow process. Semi-transparent paper, glassine, is used in place of the cellulose acetate foil. The components are stuck together with an aqueous adhesive such as carboxymethylcellulose or starch paste subsequently consolidated by pressure between heated surfaces. Langwell claims that the "Sundex" process is safer because the temperature required in bonding together the components is below that of boiling water. Second, delamination is achieved rapidly by soaking in water, without apparent damage to the document. Third, "this method produces a sandwich which is mechanically, and chemically more homogeneous than a 'Barrow' sandwich and consequently less liable to unbalanced stresses due to changes in moisture content and temperature of the atmosphere." ${ }^{31}$

The chief disadvantages of both processes is that no provision is made for

${ }^{20}$ Barrow, op. cit., p.285.

${ }^{30}$ Hummel, op. cit., p.263.

s1 William Herbert Langwell, The Conservation of Books and Documents (London: I. Pittman, 1957) p.23-24. 
deacidification prior to lamination and that the document in question might be rendered more brittle by the application of heat.

Barrow refined the conventional method of laminating with film only. $\mathrm{He}$ added, to each side of the sandwich, strong well-purified tissue, in order to give the laminate added strength and permanence. He suggested that binding margins, composed of tissue or thin paper, be incorporated along the inner margins of restored leaves of books in order to decrease the flexing and wear of restored leaves. Missing portions of leaves and worm holes could be filled in with tissue in order to give an even structural balance to the sheet. Deacidification of the document to be restored was later suggested as a prerequisite to lamination. Two effective methods of deacidification recommended by Barrow are soaking the sheet either in a solution of calcium hydroxide followed by a solution of calcium bicarbonate, or in a solution of magnesium bicarbonate. The end product provides excellent permanence and gives added strength to the document without impairing legibility. Other satisfactory features of this process are:

1. The heat used in the application of laminae kills most micro-organisms;

2. The acidity which is neutralized is not apt to become active again;

3 . The restored sheets are not difficult to use or store and can, with the addition of binding margins of tissue or good quality paper, be bound up in volumes;

4. The document or leaf can be delaminated. $^{32}$ The experience of libraries points to the fact that this process gives assurance of moderate use of

${ }^{32}$ Hummel, op. cit., p.264-66; See also Barrow, The Barrow Method of Restoring Deteriorated Documents (Richmond: 1965), for a detailed description pertaining to the procedures of deacidification and lamination. The brochure contains an excellent bibliography on this subject. restored documents over a long period of time. ${ }^{33}$

Langwell suggests the use of inhibitors in conjunction with the Sundex process in order to make provision for deacidification prior to lamination. These inhibitors would be applied to the paper in a similar fashion as those applied in the "Barrow" process except that only one bath would be needed. Inhibitors can be used together with gelatine where an improvement in both chemical and mechanical properties of paper is desirable. He states: "The use of inhibitors is too recent to gauge their effectiveness under practical conditions of archival storage. The process has, however, a sound theoretical and experimental basis and unlike the alkali impregnation, remains effective so long as the inhibitor remains in the paper. Leather has been treated in a similar way for long enough to inspire confidence in its effectiveness and there seems to be no doubt that it will be equally effective for paper." ${ }^{34}$

It would be of value at this point to indicate that conservators are making every effort to discover more facts about the composition of deteriorated papers. They are developing new materials for the preservation of materials and are also experimenting with new restorative processes. Langwell, for instance, is experimenting with vapor-phase deacidification (V.P.D.) of books and documents. $\mathrm{He}$ has found the performance of cyclohexylamine carbonate (CHC) particularly promising. ${ }^{35}$ This method may prove to be a solution to the problem of deacidification of documents containing water-soluble inks. Barrow is experimenting with print transfer. ${ }^{36}$

Foremost among the new laminating

s3 Barrow, op. cit., p.289; Leon de Valinger, "Lamination of Manuscripts at the Delaware State Archives," American Archivist, XXVIII (April 1965), 290-93; James L. Gear, "Lamination After Thirty Years," American Archivist, XXVIII (April 1965), 293-97. s4 Langwell, op. cit., p.24-25.

ss "Technical Mailbag," American Archivist, XXIX (October 1966), 566.

so Hummel, op. cit., p.266. 
films being experimented with are the following:

1. Myla. This film is flexible and has a "high edge-tear strength." It is not heat sealable, however, and must be used with an adhesive or combined with other films. The stability of the adhesive used must be taken into consideration if myla is to be used as a laminating film.

2. Polyethylene. This film is heat sealable but is difficult to delaminate. It may prove useful for materials that it will never be necessary to delaminate, but not for historical documents.

3. Myla and Polyethylene. This combination would produce a film that is flexible, strong, yet heat sealable.

4. Postlip duplex laminating tissue. This tissue consists of tissue paper impregnated with polyvinyl acetate and magnesium acetate as an acid acceptor. It was developed by W. H. Langwell with the hope that the film can laminate and deacidify at the same time. Gear states: “... no data have been compiled to show the stability of the polyvinyl acetate and it is questionable whether deacidification by this method is completely effective." ${ }^{37}$

Microfilming is not a restorative process. It can conserve the contents of the material but not the physical document which may have importance to the bibliographer or paleographer who is not interested in the contents of the material per se. It should therefore be used as a last resort for conservation purposes.

In conclusion, the conservator who considers his job completed with the restorative process he applies to the document in question, is remiss in his duties. The durability given to the document by the restorative process will come to naught if the librarian does not store the restored documents in suitable storage conditions, i.e., away from contaminated papers and atmosphere, excessive heat, uncontrolled humidity, and harmful light.

${ }^{37}$ Gear, op. cit., p.296; Hummel, op. cit., p.267.

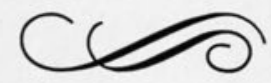

